\title{
Knowledge and Practices of Doctors About Patient Safety Working at Primary and Secondary Level Health Care Facilities in Bangladesh
}

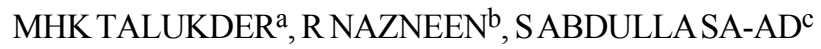

\begin{abstract}
Summary:
Aim: This descriptive type of cross sectional study was conducted with an objective to evaluate the views of doctors regarding knowledge and practices about patient safety working at primary and secondary level health care facilities in Bangladesh.
\end{abstract}

Methods: Study period was from August 2016 to December 2016. Multistage, convenience sampling was done. Sample size was 550. Self administered semi structured questionnaire was used for data collection after pre testing. Data was collected by principle investigator, co-investigator \& data collectors. Data was also collected by sending questionnaire by postage followed by a focal group discussion.

Results: Result showed $70 \%$ were male and $57 \%$ were primary level medical officers. $44.9 \%$ understands patients safety. $51.1 \%$ understands medical errors. $37.5 \%$ agreed that less duty hours will reduce medical errors. $62 \%$ strongly agreed that Learning about patient safety will enhance competency. $44.5 \%$ agreed that undergraduate course prepared them to ensure patient safety. $37.5 \%$ agreed that they learned about medical errors during their undergraduate course. $40.6 \%$ stated that they were assigned to perform the tasks for which they were not trained competently, $34 \%$ said that they were assigned to perform the tasks which could have resulted easily in medical errors.

Most of the respondents strongly agreed that teaching about patient safety should be an important priority. $46 \%$ stated that these should be in clinical teaching and $40 \%$ stated the

\section{Introduction:}

Patient safety is the prevention of errors and adverse effects to patients associated with health care. Health

1. Professor, Curriculum Development \& Evaluation, Centre for Medical Education (CME), Mohakhali, Dhaka

2. Associate Professor, Ob/Gyn Deptt, Holy Family Red Crescent Medical College and Hospital, 1 Eskaton Garden

3. Assistant Registrar Surgery, Mymensing Medical College, Road Dhaka.

Address of Correspondence: Dr. Rumana Nazneen, Associate Professor, Ob/Gyn Deptt., Holy Family Red Crescent Medical College and Hospital. Dhaka 1200. Phone Number : 01713032794, Email: rumana.nazneen@gmail.com

Received: 7 July, 2018

Accepted: 8 August, 2019 same to be in bed side teaching. $24 \%$ stated that there were not enough topics in the existing curriculum regarding patient safety. $46 \%$ confessed that they made medical errors during their practices. $33 \%$ stated that they want patient safety education in their professional practice, $\quad 76.9 \%$ strongly agreed that patient safety is an important issue in their professional practices and 44\% sensitizes their colleagues about patient safety to learn \& practices. $54.7 \%$ stated that they did not have error reporting system/death review/medical audit in their hospital, $89.7 \%$ did not have attended any training on patient safety. $90 \%$ thought that training on patient safety is essential for doctors $67.2 \%$ respondents opined that there should be a competent organization / body who can take care of patient safety \& medical errors in Bangladesh.

Conclusion: The study reflects that many primary level medical officers do not understand patients safety and medical errors. The study also showed that most of them has a positive attitude torwards patient safety.

Study recommended that doctors serving at primary and secondary level healthcare facilities to be oriented/trained on different aspects of patient safety .

Key words : Bangladesh, Knowledge and Practices of Doctors, Patient Safety, Primary and Secondary Level Health Care Facilities.

(J Bangladesh Coll Phys Surg 2020; 38: 5-11) DOI: http://dx.doi.org/10.3329/jbcps.v38i1.44682

care has evolved greatly over the past 20 years. One of the greatest challenges today is about delivering safer care in complex, pressurized and fast-moving environments with technological advancement where things can often go wrong and unintentional, but serious harm comes to patients during routine clinical practice, or as a result of a clinical decision. It is the prime responsibility of healthcare professionals to reduce harm and maintain patient safety while providing healthcare to the community.

Many patients suffer from preventable harm during the health care in hospitals and each year many people die 
from medical errors. In 2002, WHO Member States agreed on a World Health Assembly resolution on patient safety. Studies showed that additional hospitalization, litigation costs, infections acquired in hospitals, lost income, disability and medical expenses have cost some countries between US $\$ 6$ billion and US $\$ 29$ billion a year .

Professional factors such as health care professional's knowledge, attitudes and skills regarding patient safety have an impact on threats to patient safety, especially when health care professionals have an inadequate level of safety knowledge and skills to provide safe care for their patients, and also when they maintain negative attitudes to patient. To include the topic of patient safety in teaching methods, which help to develop students' attitudes, it is important to include the students and the recent graduates and their actual views in the process of curriculum development. ${ }^{1}$ There is a thought of improvement of the knowledge regarding patient safety culture among the Health care professionals and also to improve the quality of their clinical practice.

Common patient safety incidents were reported in most of the cases in the internal medicine wards and were related to medication and infusions, transfusion, contrast agent or markers, information, flow of oxygen or management, invasive treatment, accident, other treatment or monitoring. Thus this requires of further conceptual and technical developments to effective learning. In critical care settings like ICU, CCU, patient safety is mandatory to ensure a high quality of care and, and this is strongly related to the professional's knowledge .

Individual health-care providers can improve patient safety by engaging with patients and their families in a manner that shows respect, checking procedures, learning from errors and communicating effectively with other members of the health-care team. The reporting and analysis of errors can help identify the main contributing factors.

All these needs appropriate knowledge, practices and attitude of the health care provider. In a study in Germany showed that the issues of medical errors and patient safety have been rather neglected so far within medical education. The majority of German doctor would like to have more training on patient safety and medical errors.

\section{Rationale}

Medical errors and patient safety have become increasingly important in the general public as well as in the area of medical research and health policy. In Germany, the newly adopted patient's rights law governs the disclosure of medical errors, the Patient Safety and Quality of Care by the Work Group of the European Commission. This was further developed by the growing number of research articles in diverse medical subspecialties. Sometimes doctors are the ones who are likely to commit an error and have to deal with the patients, relatives and colleagues with the consequences of those errors. Also the physician himself/ herself might also be affected and, as a second victim, can also be traumatized and suffering from the error. ${ }^{10}$

To ensure patient safety by the serving doctors it is very important to assess the knowledge and practices of doctors working at primary and secondary level health care facilities. Internationally, several attempts have been made to assess doctors and medical student's knowledge, practices and attitudes towards patient safety in order to validate an instrument or to validate a single training. For Bangladesh no data on this issue has been published so far. With regard to development of knowledge for better practices about patient safety and medical errors, these issues need to be assessed. A topic such as patient safety is not only about instruction of knowledge but also about developing an attitude towards the topic. To approach the challenge of establishing contents and teaching methods, which help to develop students' attitudes, it is important to include the students and the recent graduates and their actual views in the process of curriculum development. ${ }^{1}$

\section{Objective}

\section{General objective}

To assess the knowledge and practices of doctors working at primary and secondary level health care facilities in Bangladesh about patient safety.

Specific objectives

1. To assess the knowledge of doctors working at primary and secondary level health care facilities in Bangladesh about medical errors and patient safety.

2. To explore the extent of practices of doctors working at primary and secondary level health care facilities in Bangladesh in regards to patient safety. 
3. To identify the experiences of doctors working at primary and secondary level health care facilities in Bangladesh related to patient safety

4. To find out the views of doctors about the importance of patient safety training and education working at primary and secondary level health care facilities in Bangladesh

\section{Methodology}

It was a descriptive cross-sectional study both qualitative and quantitative. Study population was the doctors working selected at primary and secondary level health care facilities of Bangladesh. Study period was 6 months (August to December, 2016). Sampling was done by multistage convenience sampling. Sample size was 517. Self-administered semi structured questionnaire was developed and finalized after pre testing outside the study area. The respondents were recruited by voluntary participation. All the data were collected anonymously and at the beginning of the distribution of the questionnaire a short briefing was given. Participation was voluntary; no material incentives were offered. Data was also collected by sending questionnaire by postage. FGD was also conducted to get in-depth views of the doctors in regards to knowledge and practices about patient safety. All data was analyzed with the SPSS version 20.0 (SPSS Inc., Chicago, IL).

\section{Focus Group Discussion (FGD)}

Following all the norms and criteria, a focus group discussion (FGD) was conducted among ten doctors working at primary and secondary level health care facilities . After effective and interactive discussion, indepth views of the doctors were obtained for the study.

\section{Results}

Table1 . Distribution of the doctors according to gender, level of service and designation . $(n=517)$
Table1 shows Among 517 doctors, 363 (70.2\%) were male and $154(29.8 \%)$ were female. 299(57.8\%) serving at primary level and $218(42.2 \%)$ doctors serving at secondary level. 417(80.7\%) of them IMO/EMO/MO, $30(5.8 \%)$ is RMO, $35(6.8 \%)$ consultant, $17(3.3 \%)$ UHFPO, 10(1.9\%) DCS and $8(1.5 \%)$ CS.

Table 2 shows that out of 517 doctors 230 (44.9\%) agreed that they have good understanding about patients safety. $260((51.1 \%)$ have good understanding about medical errors also. 190 (37.5\%) agreed and 30\% strongly agreed that less duty hour for doctors will reduce medical errors, 244 (47.7\%) agreed that patients and relatives have an important role in preventing medical errors to ensure patient safety. $62 \%$ strongly agreed that Learning about patient safety will enable them to become more competent. $220(44.5 \%)$ doctors agreed that undergraduate course prepared them to prevent medical errors to ensure patient safety. 187 (37.5 $\%$ came in contact with medical errors during their undergraduate course. 201(40.6\%) were not trained competently, during their Internship,

Table 3 shows that, most of the doctors strongly agreed that teaching medical students about patient safety should be an important priority and $40 \%$ stated the same to be in bed side teaching . $383(76.9 \%)$ strongly agreed this as an important issue in their professional practices

Table 4 shows that $283(54.7 \%)$ did not have error reporting system/ death review/medical audit in their hospital, 464 (89.7\%) did not have attended any training on patient safety within last three years, $468(90 \%)$ thought that training on patient safety is essential for doctors and $346(67.2 \%)$ thinks competent organization / body can take care of patient safety $\&$ medical errors in Bangladesh.

Table-I

Distribution of the doctors according to gender, level of service and designation . ( $n=517)$

\begin{tabular}{|c|c|c|c|c|c|c|c|c|}
\hline \multicolumn{2}{|c|}{ Gender } & \multicolumn{2}{|c|}{ Level of service } & \multicolumn{5}{|c|}{ Designation } \\
\hline Male & Female & $\begin{array}{c}\text { Primary } \\
\text { level }\end{array}$ & $\begin{array}{c}\text { Secondary } \\
\text { level }\end{array}$ & $\begin{array}{c}\mathrm{IMO} / \\
\mathrm{EMO} / \mathrm{MO}\end{array}$ & RMO & $\begin{array}{c}\text { Consultant } \\
\text { UHFPO }\end{array}$ & DCS & CS \\
\hline 363 & 154 & 299 & 218 & 417 & 30 & 35 & 10 & 8 \\
\hline$(70.2 \%)$ & $(29.8 \%)$ & $(57.8 \%)$ & $(42.2 \%)$ & $(80.7 \%)$ & $(5.8 \%)$ & $(6.8 \%)$ & $(1.9 \%)$ & $(1.5 \%)$ \\
\hline
\end{tabular}


Table-II

Shows that out of 517 doctors 230 (44.9\%) agreed that they have good

\begin{tabular}{|c|c|c|c|c|c|c|c|}
\hline $\begin{array}{l}\text { Doctors views about } \\
\text { patient safety issues }\end{array}$ & $\begin{array}{l}\text { Strongly } \\
\text { disagree }\end{array}$ & $\begin{array}{c}1 \\
\text { Disagree }\end{array}$ & $\begin{array}{c}2 \\
\text { Neither } \\
\text { agree } \\
\text { nor disagree }\end{array}$ & $\begin{array}{c}3 \\
\text { Agree } \\
\end{array}$ & $\begin{array}{c}4 \\
\text { Strongly } \\
\text { agree }\end{array}$ & $\begin{array}{c}5 \\
\text { Total }\end{array}$ & $\begin{array}{l}\text { Mean } \\
(\mathrm{SD} \pm)\end{array}$ \\
\hline & $f(\%)$ & $f(\%)$ & $\mathrm{f}(\%)$ & $f(\%)$ & $f(\%)$ & & \\
\hline $\begin{array}{l}\text { Understands patient } \\
\text { safety issues }\end{array}$ & $\begin{array}{c}17 \\
(3.3 \%)\end{array}$ & $\begin{array}{c}43 \\
(8.4 \%)\end{array}$ & $\begin{array}{c}58 \\
(11.3 \%)\end{array}$ & $\begin{array}{c}230 \\
(44.9 \%)\end{array}$ & $\begin{array}{c}164 \\
(32 \%)\end{array}$ & 512 & $\begin{array}{c}3.94 \\
1.033\end{array}$ \\
\hline $\begin{array}{l}\text { Understands medical } \\
\text { errors }\end{array}$ & $\begin{array}{c}17 \\
(3.3 \%)\end{array}$ & $\begin{array}{c}61 \\
(12 \%)\end{array}$ & $\begin{array}{c}88 \\
(17.3 \%)\end{array}$ & $\begin{array}{c}260 \\
(51.1 \%)\end{array}$ & $\begin{array}{c}83 \\
(16.3 \%)\end{array}$ & 509 & $\begin{array}{l}3.65 \\
.998\end{array}$ \\
\hline $\begin{array}{l}\text { Less duty hour (shift) for } \\
\text { doctors will reduce } \\
\text { medical errors. }\end{array}$ & $\begin{array}{c}36 \\
(7.1 \%)\end{array}$ & $\begin{array}{c}68 \\
(13.4 \%)\end{array}$ & $\begin{array}{c}58 \\
(11.5 \%)\end{array}$ & $\begin{array}{c}190 \\
(37.5 \%)\end{array}$ & $\begin{array}{c}154 \\
(30.4 \%)\end{array}$ & 506 & $\begin{array}{c}3.71 \\
1.231\end{array}$ \\
\hline $\begin{array}{l}\text { Learning about patient } \\
\text { safety issues will } \\
\text { increase their } \\
\text { competencies. }\end{array}$ & $\begin{array}{c}7 \\
(1.4 \%)\end{array}$ & $\begin{array}{c}7 \\
(1.4 \%)\end{array}$ & $\begin{array}{c}20 \\
(4 \%)\end{array}$ & $\begin{array}{c}156 \\
(30.9 \%)\end{array}$ & $\begin{array}{c}315 \\
(62.4 \%)\end{array}$ & 505 & $\begin{array}{l}4.51 \\
.761\end{array}$ \\
\hline $\begin{array}{l}\text { Learned about medical } \\
\text { errors and patient safety } \\
\text { in Undergraduate course }\end{array}$ & $\begin{array}{c}53 \\
(10.7 \%)\end{array}$ & $\begin{array}{c}87 \\
(17.6 \%)\end{array}$ & $\begin{array}{c}57 \\
(11.5 \%)\end{array}$ & $\begin{array}{c}220 \\
(44.5 \%)\end{array}$ & $\begin{array}{c}77 \\
(15.6 \%)\end{array}$ & 494 & $\begin{array}{l}3.37 \\
1.242\end{array}$ \\
\hline $\begin{array}{l}\text { Was not trained } \\
\text { competently to deal with } \\
\text { patient's safety issues } \\
\text { during Internship. }\end{array}$ & $\begin{array}{c}51 \\
(10.3 \%)\end{array}$ & $\begin{array}{c}106 \\
(21.4 \%)\end{array}$ & $\begin{array}{c}65 \\
(13.1 \%)\end{array}$ & $\begin{array}{c}201 \\
(40.6 \%)\end{array}$ & $\begin{array}{c}72 \\
(14.5 \%)\end{array}$ & 495 & $\begin{array}{c}3.28 \\
1.241\end{array}$ \\
\hline
\end{tabular}

Table-III

Doctors views regarding the teaching of patient safety. $n=517$

\begin{tabular}{|c|c|c|c|c|c|c|c|}
\hline $\begin{array}{l}\text { Doctors views about } \\
\text { teaching of patient safety }\end{array}$ & $\begin{array}{l}\text { Strongly } \\
\text { disagree }\end{array}$ & $\begin{array}{c}1 \\
\text { Disagree }\end{array}$ & $\begin{array}{c}2 \\
\text { Neither } \\
\text { agree } \\
\text { nor disagree }\end{array}$ & $\begin{array}{c}3 \\
\text { Agree }\end{array}$ & $\begin{array}{c}4 \\
\text { Strongly } \\
\text { agree }\end{array}$ & $\begin{array}{c}5 \\
\text { Total }\end{array}$ & $\begin{array}{l}\text { Mean } \\
(\mathrm{SD} \pm)\end{array}$ \\
\hline & $f(\%)$ & $f(\%)$ & $f(\%)$ & $f(\%)$ & $f(\%)$ & & \\
\hline $\begin{array}{l}\text { Teaching about patient } \\
\text { safety should be an } \\
\text { important priority. }\end{array}$ & $\begin{array}{c}10 \\
(2 \%)\end{array}$ & $\begin{array}{c}3 \\
(.6 \%)\end{array}$ & $\begin{array}{c}3 \\
(.6 \%)\end{array}$ & $\begin{array}{c}126 \\
(24.8 \%)\end{array}$ & $\begin{array}{c}367 \\
(72.1 \%)\end{array}$ & 509 & $\begin{array}{l}4.64 \\
.716\end{array}$ \\
\hline $\begin{array}{l}\text { Topics of Patient safety } \\
\text { should be included } \\
\text { formally in the } \\
\text { curriculum }\end{array}$ & $\begin{array}{c}12 \\
(2.4 \%)\end{array}$ & $\begin{array}{c}12 \\
(2.4 \%)\end{array}$ & $\begin{array}{c}18 \\
(3.6 \%)\end{array}$ & $\begin{array}{c}173 \\
(34.9 \%)\end{array}$ & $\begin{array}{c}281 \\
(56.7 \%)\end{array}$ & 496 & $\begin{array}{l}4.41 \\
.861\end{array}$ \\
\hline $\begin{array}{l}\text { Bed side teaching may } \\
\text { be the right method to } \\
\text { teach about patient safety }\end{array}$ & $\begin{array}{c}30 \\
(6.1 \%)\end{array}$ & $\begin{array}{c}42 \\
(8.5 \%)\end{array}$ & $\begin{array}{c}39 \\
(7.9 \%)\end{array}$ & $\begin{array}{c}187 \\
(37.8 \%)\end{array}$ & $\begin{array}{c}197 \\
(39.8 \%)\end{array}$ & 495 & $\begin{array}{l}3.97 \\
1.168\end{array}$ \\
\hline $\begin{array}{l}\text { Patient safety is an } \\
\text { important issue in } \\
\text { professional practices }\end{array}$ & $\begin{array}{c}11 \\
(2.2 \%)\end{array}$ & $\begin{array}{c}11 \\
(2.2 \%)\end{array}$ & $\begin{array}{c}8 \\
(1.6 \%)\end{array}$ & $\begin{array}{c}85 \\
(17.1 \%)\end{array}$ & $\begin{array}{c}383 \\
(76.9 \%)\end{array}$ & 498 & $\begin{array}{c}3.14 \\
1.356\end{array}$ \\
\hline
\end{tabular}


Table-IV

\begin{tabular}{|c|c|c|c|}
\hline \multicolumn{4}{|c|}{ Views of the doctors about the practice of patient safety. } \\
\hline Different aspects of patient safety. & $\begin{array}{l}\text { Frequency } \\
\text { Yes }\end{array}$ & $\begin{array}{l}\mathrm{N}(\%) \\
\text { No }\end{array}$ & Total \\
\hline Have error in reporting system/ death & 234 & 283 & 517 \\
\hline review/ medical audit in hospital & $(45.3 \%)$ & $(54.7 \%)$ & \\
\hline $\begin{array}{l}\text { Have attended any training on patient } \\
\text { safety within last three years }\end{array}$ & $\begin{array}{c}53 \\
(10.3 \%)\end{array}$ & $\begin{array}{c}464 \\
(89.7 \%)\end{array}$ & 517 \\
\hline $\begin{array}{l}\text { Think that training on patient safety is } \\
\text { essential for doctors }\end{array}$ & $\begin{array}{c}468 \\
(90.5 \%)\end{array}$ & $\begin{array}{c}49 \\
(9.5 \%)\end{array}$ & 517 \\
\hline $\begin{array}{l}\text { Competent organization / body can take } \\
\text { care of patient safety \& medical errors in Bangladesh }\end{array}$ & $\begin{array}{c}169 \\
(32.8 \%)\end{array}$ & $\begin{array}{c}346 \\
(67.2 \%)\end{array}$ & 517 \\
\hline
\end{tabular}

\section{Discussion}

Out of 517 doctors $230(44.9 \%)$ agreed and 164(32\%) strongly agreed that they have good understanding about patients safety related issue. Around 260 (51.1\%) also agreed that they have good understanding about medical errors also. This is similar to PHCC doctors in Aseer region showed a positive attitude toward patient safety.

Among 517 doctors 190 (37.5\%) agreed and 154 (30.4\%) strongly agreed that less duty hour (shift) for doctors will reduce medical errors. In a study done by Sultan M et al showed that $47 \%$ respondents agreed to this statement. ${ }^{1}$ In the few PHCC with a high number of patients attending and work overload, participants showed that a shorter shift for the doctors and taking breaks would reduce medical error. ${ }^{15}$ These findings agree with those reported by Carruthers et al. Error! Bookmark not defined.

Among the total doctors $220(44.5 \%)$ agreed that undergraduate course prepared them to prevent medical errors to ensure patient safety. This finding is similar to the findings of Sultan, (39\%). ${ }^{1}$ Around 201(40.6\%) agreed that they were not trained competently to deal with patient's safety issues during internship. This is similar to the study of Sultan (52\%). ${ }^{1}$ Sultan's study showed around $57 \%$ for the same reason. Regarding the teaching of medical students about patient safety as an important priority and should be included formally in the curriculum as bed side or clinical teaching, the results are comparable to the study of sultan (43\%). ${ }^{1}$ Carruthers et al. developed an instrument to assess the attitude of students and tutors towards patient safety and tested its validity and reliability. Error! Bookmark not defined.

Most of the doctors strongly agreed that teaching medical students about patient safety should be an important priority in the curriculum . Leung \& Patil in Hong Kong emphasized the priority of putting patient safety in the undergraduate curriculum of medical colleges . Students regarded patient safety as an important topic that should be included in undergraduate teaching and professional examinations. $383(76.9 \%)$ strongly agreed that patient safety is an important issue in their professional practices and 217 (44\%) . In a study in Aseer region in Saudi Arabia 70\% had not attended any training course on patient safety. Error! Bookmark not defined. Such important findings indicate that there is urgent need for such interventions as conducting continuous professional development programs on "medical errors and patient safety" for intern doctors. In a study in Germany majority of respondents $(64 \%)$ wished for more education on the issues. ${ }^{10}$ A study by Almaramhy et al. mentioned that more than two thirds of medical students agreed that the teaching of patient safety in medical schools and the continuous training of health staff was necessary. Error! Bookmark not defined. Another study showed that $87.8 \%$ doctors agreed that learning about patient safety before graduation from medical colleges would produce more effective doctors. ${ }^{1}$

Among 517 respondents, 283(54.7\%) did not have error reporting system/death review/medical audit in their hospital, 464 (89.7\%) did not have attended any training on patient safety within last three years, $468(90 \%)$ 
thought that training on patient safety is essential for doctors serving at different level of health care facilities. Whereas $84.8 \%$ of the intern doctors agreed that teaching students about patient safety should be a priority in medical students training ${ }^{1}$. 346(67.2\%) respondents opined that there is no competent organization / body who can take care of patient safety $\&$ medical errors in Bangladesh. This finding is similar to the findings in other studies of Al-Khaldi . ${ }^{15}$

\section{Conclusion :}

This study showed that doctors serving at primary \& secondary health care facilities had positive attitude toward patient safety. Most of the respondents considered patient safety as a priority topic for training and undergraduate medical education. Among the doctors attended this study, there was a distinct need for more training on patient safety. They did not feel sufficiently trained for working as physicians especially in dealing with medical errors to ensure patient safety and in their communication. Doctors did not have adequate knowledge on this issue of patient safety and were positive about teaching patient safety according to WHO guidelines. They also agreed to include patient safety in the curriculum specially in the later part of the course \& internship.

\section{Limitations}

- As convenience sampling was done, findings cannot be generalized.

- As data were collected from limited districts, results do not represent the whole country.

- An anonymous survey is considered as an appropriate method, due to the sensitivity of the issue and to minimize the negative effect of social desirability, the study has some limitations.

- As more interested doctors participated in the study, it might have caused a possible limitation of the study influencing the results.

- Time and money are also considered as factors of limitation.

\section{Recommendations}

Doctors serving at primary and secondary level healthcare facilities to be oriented/trained on different aspects of patient safety.

Introducing clinical audit, death audit, medical errors audit will ensure the practice of patient safety
Reporting medical errors to ensure and improve patient safety should be developed as a culture can be made mandatory.

An expert committee should be formed to decide on how WHO patient safety guidelines can be integrated to our curriculum on the basis of our national need.

Further studies are needed to explore the knowledge and practices of physicians on patient safety and medical errors.

\section{Acknowledgement:}

We thank all our colleagues and the other professional staffs for the supports they extended in doing this work.

\section{References:}

1 Sultana M, Hossain S, Ara I , Sultana J . Medical Errors and Patient Safety Education: Views of Intern Doctors. Bangladesh Medical Research Counc. Bull 201844.82-88. DOI: http://dx.doi.org/10.3329/ bmrcb.v44i2.38701

2 Nie Y, Li L, Duan Y, Chen P, et al. Patient safety education for undergraduate medical students: a systematic review. BMC Med Educ. 2011;11:33.

3 Brasaite et al. Health care professionals' attitudes regarding patient safety: cross- sectional survey. BMC Res Notes (2016) 9:177 DOI 10.1186/s13104-0161977-7

4 World Health Organization 2011. WHO patient safety curriculum guide: multi- professional edition. available at (www.who.int)

5 Robson J, de Wet C, McKay J, et.al.. Do we know what foundation year doctors think about patient safety incident reporting? Development of a web based tool to assess attitude and knowledge.Postgrad Med J. 2012;87:750-6

6 Bagnasco A, Tibaldi L, Chirone P . et al. Patient safety culture: an Italian experience. Journal of Clinical Nursing, 2011 20: 1188-1195.

7 Kinnunen-Luovi K, Saarnio R, Isola, A. Safety incidents involving confused and forgetful older patients in a specialised care setting - analysis of the $\mathrm{s}$ a $\mathrm{f}$ e $\mathrm{t} y$ incidents reported to the HaiPro reporting system. Journal of Clinical Nursing, 2014 . 23: 2442-2450

8 Larizgoitia I, Bouesseau MC, Kelley E. WHO Efforts to Promote Reporting of Adverse Events and Global Learning. Journal of Public Health Research, $2 \begin{array}{llll}0 & 1 & 3\end{array}$. 2(3): e29.

9 Baid H, Hargreaves J. Quality and safety: reflection on the implications for critical care nursing education. British Association of Critical Care Nurses, 2015 20(4): 174-182. 
10 Kiesewetter J, Kager M, Lux R, et al. German undergraduate medical students' attitudes and needs regarding medical errors and patient safety - A national survey in Germany. Medical Teacher 2014;36:505-10.

11 Youn. 2011. Why you should never go to the hospital in July [Online].

[Accessed 6 December 2012] Available from http:// thechart.blogs.cnn.com/2011/06/22/

12

Shekelle PG, Pronovost PJ, Wachter RM, Mcdonald KM, Schoelles K, DySM, Shojania K, Reston JT, Adams AS, Angood PB. 2013. The top patient safety strategies that can be encouraged for adoption now. Ann Intern Med 158:365-368.

13 Truog RD, Browning DM, Johnson JA, Gallagher TH. 2010. Talking with patients and families about medical error: A guide for education and practice. Baltimore: JHU Press.

14 Arora S, Sevdalis N, Ahmed M, Wong H, Moorthy K, Vincent
C. 2012. Safetyskills training for surgeons: A halfday intervention improves knowledge, attitudes and awareness of patient safety. Surgery 152:26- 31 .

15 Al-Khaldi YM. Attitude of primary care physicians toward patient safety in Aseer region, Saudi Arabia. J Fam Community Med [serial online] 2013 [cited 2014 Aug 27];20:153-8.

16 Leung GK, Patil NG. 2010. Patient safety in the undergraduate curriculum: Medical students' perception. Hong Kong Med J 16:101- 105.

17 Liu C, Liu W, Wang Y, Zhang Z, Wang P. (2014) Patient safety culture in China: a case study in an outpatient setting in Beijing. BMJ Quality \& Safety, 23: $556-564$ 